\title{
Development of the Mediterranean extinction code (MEDEX)
}

\author{
Jacques Piazzola \\ Frédéric Bouchara \\ University of Toulon-Var \\ LEPI \\ B.P. 132 \\ 83957 La Garde cedex, France
}

\section{Gerrit de Leeuw}

Alexander M. J. Van Eijk

TNO Physics and Electronics Laboratory

P.O. Box 96864

The Hague, NL-2509 JG

The Netherlands

\begin{abstract}
The performance of electro-optical systems can be substantially affected by aerosol particles that scatter and absorb electromagnetic radiation. The model that is most frequently used for the prediction of aerosols and their effect on extinction in the marine atmosphere is the US Navy Aerosol Model (NAM). However, NAM can be significantly less reliable in coastal areas than on the open ocean. Based on an extensive series of measurements conducted on the island of Inisheer (Irish West Coast), an empirical aerosol model for the coastal zone formulated as an extension of NAM, in which coastal effects are modeled as a function of fetch, has been developed. This work is extended to the Mediterranean using an aerosol dataset recorded on the island of Porquerolles in the Bay of Toulon (France) and has been coupled with the Mie theory to give a code for the extinction, the code MEDiterranean EXtinction (MEDEX). (c) 2003 Society of Photo-Optical Instrumentation Engineers. [DOI: 10.1117/1.1556765]

Subject terms: coastal aerosols; optical propagation; NAM; fetch.
\end{abstract}

Paper 020246 received Jun. 18, 2002; revised manuscript received Oct. 7, 2002; accepted for publication Oct. 8, 2002.

\section{Introduction}

The performance of a given electro-optical system is to a large extent determined by the atmospheric conditions. For good visibility, i.e., low aerosol concentrations, the detection range is in general large, and vice versa, in adverse visibility conditions, the detection range may be small. In addition, atmospheric refraction effects may heavily impact target detection probability. For example, under subrefractive conditions, targets close to the sea surface that can be seen under neutral conditions cannot be observed at certain ranges irrespective of the visibility.

The visibility is determined by both molecules and aerosols. Molecular effects are relatively well quantified and can be calculated using propagation codes such as MODTRAN. ${ }^{1}$ Aerosols are much less well characterized, especially because their concentrations and optical properties (chemical composition) are very variable both in time and space. Effects of aerosols and refractivity on transmission in the coastal environment have been analyzed based on field experiments along the Californian coast. ${ }^{2}$ The results show that refractive effects are the primary parameter influencing near-surface propagation, while aerosols can also have a very large effect in this coastal region. ${ }^{3}$ The electro-optical propagation codes IRBLEM ${ }^{4}$ and EOSTAR $^{5}$ aim at a description of these effects by including both refraction and extinction due to gases and aerosols for the marine environment.

The previously mentioned MODTRAN code describes the attenuation of electro-optical radiation by gases and aerosols. Over the ocean, MODTRAN uses the Navy Aerosol Model (NAM) ${ }^{6}$ and the Naval Oceanic Vertical Aerosol Model (NOVAM). ${ }^{7}$ NAM is the kernel for NOVAM, which in turn is used to extend NAM from about $10-\mathrm{m}$ above sea level to the top of the boundary layer, and it is based on atmospheric models describing the boundary layer structure and aerosol transport. NAM is currently being upgraded to the Advanced Navy Aerosol Model (ANAM), ${ }^{8}$ which provides a better description of large aerosols and allows extension downwards to the surface. ANAM is presently not available in MODTRAN, but has been included in EOSTAR.

We focus on aerosol effects on propagation in the coastal environment, building on the work of Piazzola, Van Eijk, and De Leeuw ${ }^{9}$ to include coastal effects in the Navy Aerosol Model (NAM). ${ }^{6}$ NAM is mainly based on data collected prior to 1983 . In general, NAM provides reasonable predictions for extinction over the open ocean, but in coastal regions they are often less reliable $e^{9,10}$ when, in an off-shore wind, continental aerosols mix with the sea spray. Since NAM was developed from mainly open ocean data, the model cannot be expected to cover such situations. Piazzola, Van Eijk, and De Leeuw ${ }^{9}$ proposed an extension of the Navy Aerosol Model based on the analysis of an extensive series of measurements on the island of Inisheer off the Irish Atlantic Coast. This work extends NAM with a similar analysis using data collected on the island of Porquerolles off the French Mediterranean Coast. The results were used to develop the extinction model MEDEX (Mediterranean Extinction). The results are compared with those from the Inisheer dataset to explore potential generalization. The analysis of the two datasets also leads to a better understanding of the similarities and differences between different coastal zones.

\section{Field Site and Instrumentation}

Measurements of aerosol particle size distributions and supporting meteorological parameters were made at the island of Porquerolles in the Mediterranean Sea near Toulon [Fig. 1(a)]. The experimental station is located at the ex- 


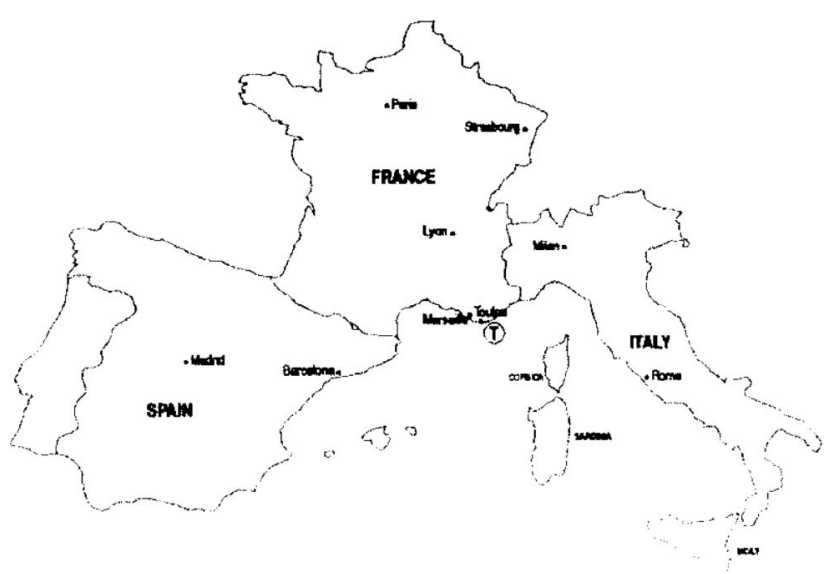

(a)

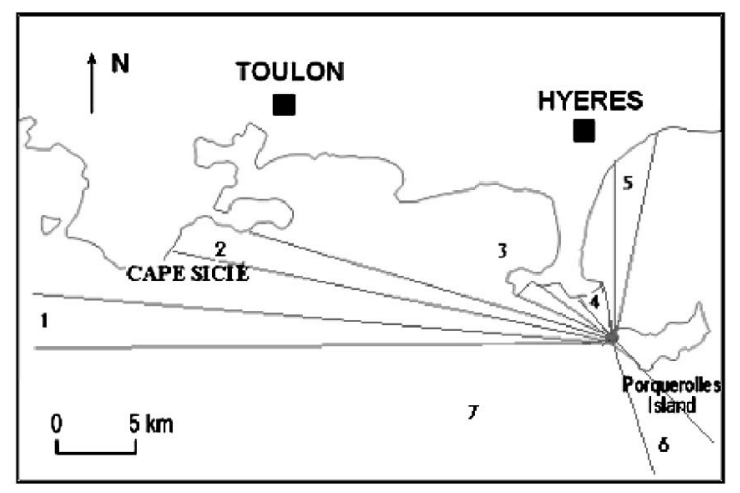

(b)

Fig. 1 (a) Experimental site on the French Mediterranean Coast. The site of the experiment is marked by a T. (b) Detailed view of the study area including the five wind direction intervals used in the present analysis. The wind sectors are numbered from 1 to 7 . Only the wind sectors numbered from 1 to 5 were used to elaborate the Mediterranean model.

treme west point of the island [Fig. 1(b)]. Figure 1(b) clearly shows that the sea state depends on the wind's trajectory over water, i.e., the fetch. The station is exposed to air masses from the open sea, which corresponds to infinite fetches as defined by the criterion applied for fully developed sea conditions, ${ }^{11,12}$ as well as to air masses originating over the European mainland, with a very short fetch (about $5 \mathrm{~km}$ ) over sea, which represent continentally polluted conditions. Fetch limited conditions occur for local wind directions between 290 and $30 \mathrm{deg}$ [sections 2, 3, 4, and 5 in Fig. 1(b)], whereas the 160 to $220 \mathrm{deg}$ wind direction interval (sections 6 and 7) generally corresponds to open waters. To elaborate the coastal model for the Mediterranean as presented in this work, we needed a large number of measured aerosol distributions for each fetch, and hence, each wind sector encountered during the trial period. In addition, these data should cover a wind speed interval that is large enough to be representative for the conditions at Porquerolles. This is why only five of the wind direction intervals reported in Fig. 1(b) were used to calculate the regression laws constituting the model (see paragraph 4).

For west and southwest winds, corresponding to local directions varying from 220 to $270 \mathrm{deg}$, we used calculations of the air mass trajectory, provided by Meteo France's

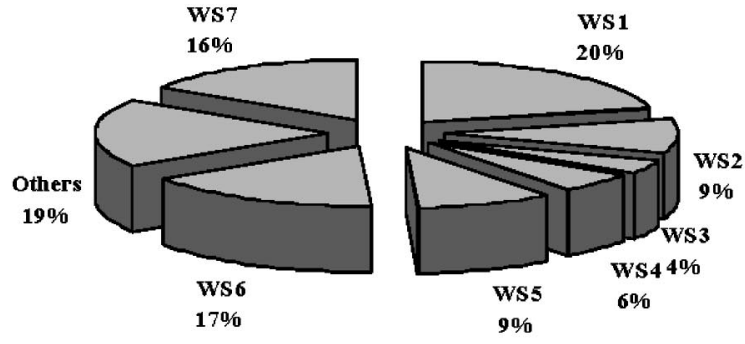

(a)

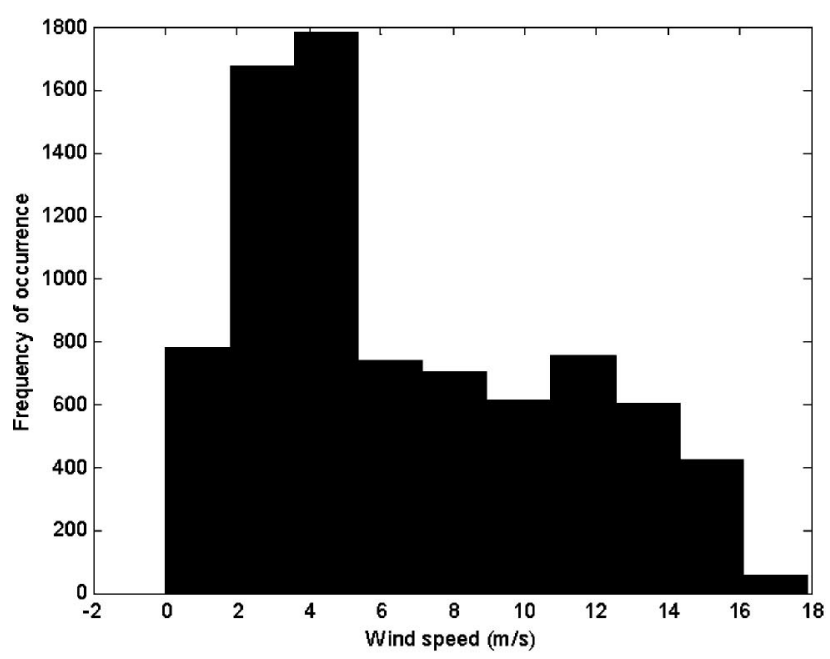

(b)

Fig. 2 (a) Pie chart representing the frequency of occurrence of each wind direction as numbered in the area map of Fig. 1(b). (b) Frequency of occurrence of the wind speeds during the measurements period.

numerical model, to determine the real fetch. Indeed, the fetch for these wind directions can range from $100 \mathrm{~km}$ to an almost unlimited fetch (open water conditions).

Figure 2(a) shows the frequencies of occurrence (in percent) of the five wind direction intervals included in the present analysis. Figure 2(b) shows the frequency of occurrence of the wind speeds during the measurement period. The prevailing wind directions in the study area are eastsoutheast and northwest. However, as shown in Fig. 2, a large variety of wind directions were encountered during the experimental campaign. Hence, combining the information in Figs. 1 and 2, also the fetches during the experimental period, varied widely. West and northwest local wind directions dominated, corresponding to fetches of 25 to 100 $\mathrm{km}$. More than $30 \%$ of the time fetches were shorter than $25 \mathrm{~km}$. Although the present results are for a measurement period of only two months, the wind direction distribution is similar to that reported by Piazzola ${ }^{13}$ for the same experimental area over a period of one year.

Size distributions of particles with diameters between 0.1 and $42.5 \mu \mathrm{m}$ were measured at the Porquerolles site with two classical scattering spectrometer probes (Particle Measuring Systems, Boulder, CO), the CSASP-200 and the CSASP-100HV. The aerosol counters and meteorological sensors were located at heights of 25 and $30 \mathrm{~m}$, respectively, above the sea surface. Aerosol data were sampled during 1-min intervals and were subsequently averaged and 


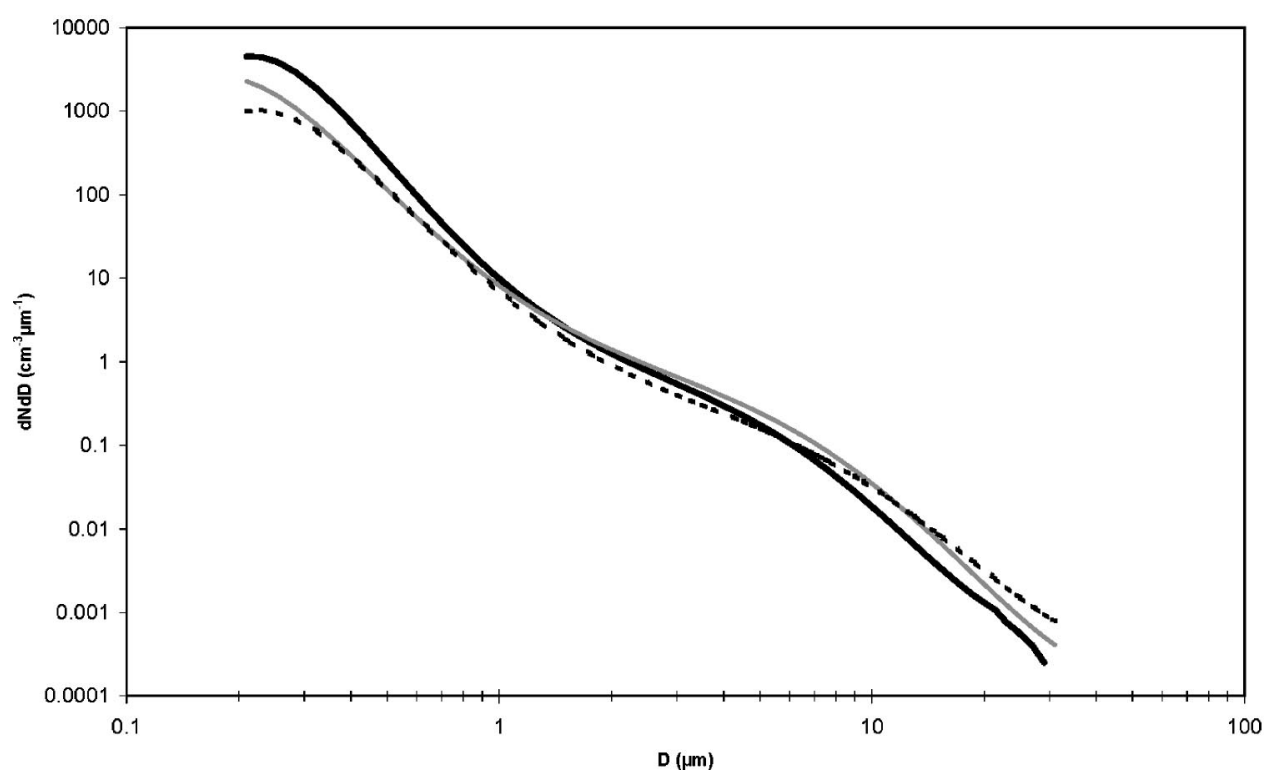

Fig. 3 Examples of polynomial representations of particle size distributions recorded during the campaign. The figure shows aerosol size distributions recorded for a wind speed of $10 \mathrm{~m} / \mathrm{s}$ at various fetches. The thick black curve represents the size distribution recorded for a fetch of $13 \mathrm{~km}$, the gray line is the data measured for a fetch of $25 \mathrm{~km}$, and the dashed line is for a $100-\mathrm{km}$ fetch.

stored as 4-min averages. Meterological data measured at the site were wind speed, wind direction, air and sea temperature, and relative humidity. Data were collected during two months, in the period between November 2000 and February 2001. Because of the remoteness of the site, the data were collected unattended. Accounting for losses due to down time, about 1000 hours of data were acquired between the end of November 2000 and early February 2001.

\section{Typical Aerosol Size Distributions in the Mediterranean Coastal Zone}

Aerosol size distributions and meteorological parameters were continuously recorded. Polynomial fits of first and fifth order in $\log (\mathrm{dN} / \mathrm{dD})$ versus Log $(\mathrm{D})$ space were made to the distributions to facilitate the analysis. Polynomial representations of aerosol distributions recorded for different fetches at a wind speed of about $10 \mathrm{~m} / \mathrm{s}$ are shown in Fig. 3. The concentrations of coarse particles $(>1 \mu \mathrm{m})$, which at longer fetch are assumed to be dominated by seasalt particles, increase with increasing fetch. This effect becomes more prominent as particle size increases. In contrast, the concentrations of submicrometer particles decrease at larger fetch. The data in Fig. 3 is an example of the transition from a continental to a marine aerosol as the air mass is advected over the sea, similar to observations by Vignati et al. ${ }^{14}$ and Van Eijk and De Leeuw ${ }^{15}$ in other coastal locations.

Figure 4 shows the variations of the aerosol size distribution with wind speed for two fetches. To eliminate the effects of $\mathrm{RH}$, the aerosol concentrations were normalized to $80 \%$ relative humidity using equations formulated by Fitzgerald. ${ }^{16}$ For a fetch of $25 \mathrm{~km}$, Fig. 4(a) shows that the concentration of coarse particles increases with wind speed. This is ascribed to the increased production of sea salt droplets at the surface. The concentrations of the submi- crometer particles decrease slightly as the wind speed increases. For such short fetches, the land-originated particles prevail in the submicron range and their concentrations increase with decreasing wind speeds due to accumulation caused by slower dispersion. ${ }^{14,17}$ For a fetch of about 100 km, Fig. 4(b) shows that the concentration of supermicron particles has a similar behavior with wind speed, as noted in Fig. 4(a). For submicron particles, the slight decrease with wind speed is still present at the smallest particle sizes when the wind speed increases from 8 to $12 \mathrm{~m} / \mathrm{s}$. For higher wind speeds $(>15 \mathrm{~m} / \mathrm{s})$, however, we note an increase of the submicrometer particles with wind speed. This is probably due to the enhancement of the marine contribution in this size range. Although the submicron particles at shorter fetches are predominantly from continental origin, submicron sea spray production has been observed. ${ }^{17-20}$

As shown above, the aerosol size distributions measured at Porquerolles clearly show the influence of fetch and wind speed. The shape of the particle size distributions changes due to changing relative contributions of marine and land-originated aerosols with increasing fetch. The concentrations are determined by the balance between production and removal. The production varies with the wind speed, roughly as $u_{*}^{3}$ (e.g., Andreas, 1998), ${ }^{21}$ whereas for a source from above the deposition velocity is parameterized as linearly dependent on the wind speed. ${ }^{22}$

\section{Mediterranean Aerosol Model}

The Mediterranean aerosol model is based on an extensive series of measurements, described before, which were acquired on Porquerolles island from November 2000 to February 2001. This extended period allowed for the observation of a large variety of aerosol size distributions under different meteorological conditions. The experimental data 


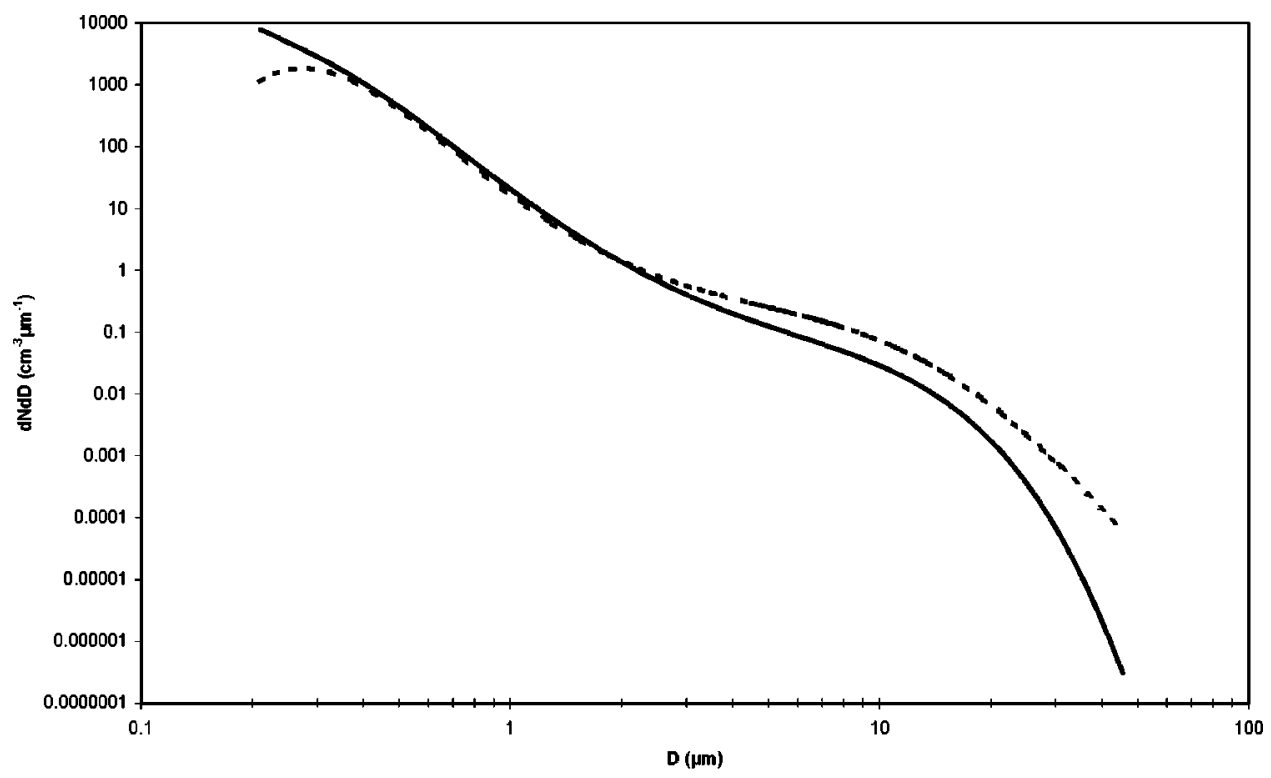

(a)

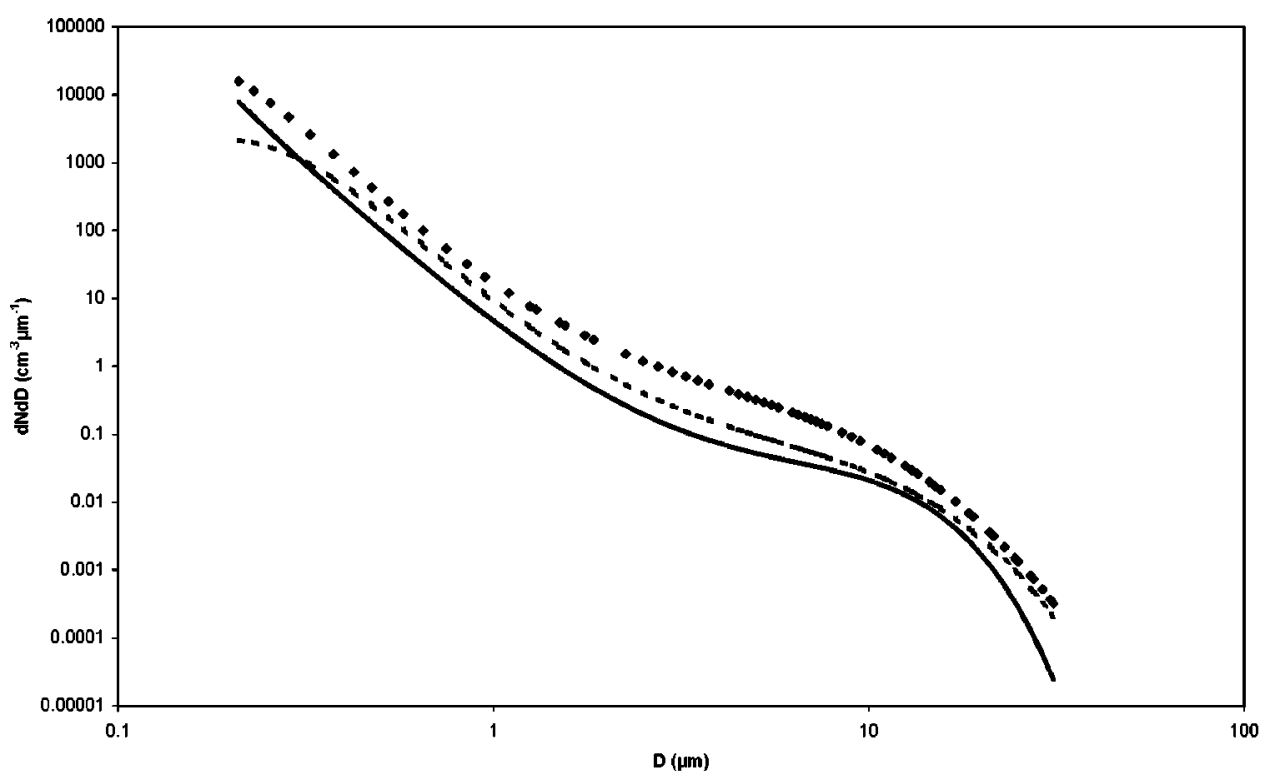

(b)

Fig. 4 (a) Polynomial representations of aerosol size distributions recorded for a fixed fetch of $25 \mathrm{~km}$ and different wind speeds. The line represents the aerosol size distribution recorded at a wind speed of $7 \mathrm{~m} / \mathrm{s}$, while the dashed one represents data recorded for a wind speed of $16 \mathrm{~m} / \mathrm{s}$. The aerosol spectra are normalized to a relative humidity of $80 \%$. (b) the same as Fig. 4(a) for a fetch of $100 \mathrm{~km}$. The line represents the data recorded at a wind speed of $8 \mathrm{~m} / \mathrm{s}$, while the dashed curve is for wind speed of about $12 \mathrm{~m} / \mathrm{s}$, and the diamonds represent an aerosol size distribution measured in a wind speed of $15.5 \mathrm{~m} / \mathrm{s}$.

from Porquerolles were statistically analyzed to develop an empirical coastal aerosol model for implementation into MEDEX. The Mediterranean model is formulated analogously to the Inisheer model proposed by Piazzola, Van Eijk, and De Leeuw, ${ }^{9}$ i.e., as a modification of the Navy Aerosol Model (NAM). ${ }^{6}$ As in NAM, the aerosol concentration $N(r)$ is calculated as the sum of lognormal functions, but the amplitudes of the various modes are parameterized as functions of fetch. This approach allows for coastal influence in all modes, whereas in NAM, the con- tinental influence was limited to the first mode describing the smallest particles. The coastal zone not only affects the concentrations of the submicron particles (originating over land), but also those of the larger particles, i.e., sea spray produced by breaking waves, which in turn depend on wave age and fetch. ${ }^{23}$ Furthermore, as suggested by De Leeuw, ${ }^{24}$ a fourth mode has been introduced to model the largest sea spray particles. As shown in Fig. 5, the aerosol concentration $N(r)$ is then calculated as the sum of four lognormal functions: 


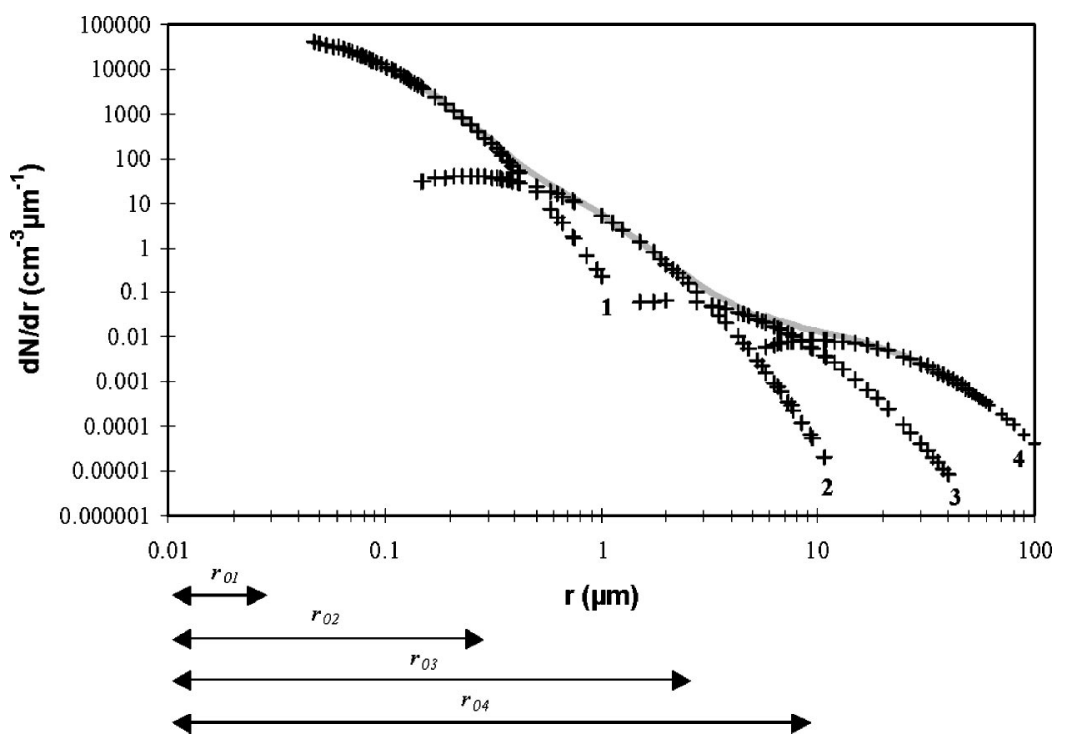

Fig. 5 The modeled aerosol spectrum (the gray line) as defined in Eq. (1). The crosses represent the fourth lognormal functions, numbered directly on the graph.

$$
N(r)=\sum_{i=1}^{4} \frac{A_{i}}{f} \exp \left\{-C_{i}\left[\ln \left(r / f r_{o i}\right)\right]^{2}\right\}
$$

where $r_{01}=0.03, r_{02}=0.24, r_{03}=2 \mu \mathrm{m}, r_{04}=10 \mu \mathrm{m}, f$ represents the humidity growth factor, ${ }^{25} A_{i}$ denotes the $i$ th mode amplitude, and $C_{i}$ is the width of the $i$ th mode.

To determine the effect of fetch on the aerosol concentrations, the aerosol data were sorted into five wind direction intervals [Fig. 1(b)]. For each sector, the amplitude of the first mode, $A_{1}$, was directly related to the fetch [resulting in Eq. (2)]. The fetch dependence of mode amplitudes $A_{2}, A_{3}$, and $A_{4}$ was determined using linear regression on the concentration versus wind speed for particles of $0.24,2$, and $10 \mu \mathrm{m}$ radius. Having obtained the parameterization of mode amplitudes $A_{2}, A_{3}$, and $A_{4}$, the four widths, $C_{i}$, were obtained from a multivariable fit to the experimental size distributions as functions of wind speed and fetch. Optimization of the widths was obtained by assuming a limited range of variations of the mode radii, since they correspond to a physical characteristic of the aerosol size distributions. Subsequently, plots of the regression parameters (slopes and intercepts of the concentration/wind speed plots) versus fetch were fitted to an exponential function. This procedure resulted in mode amplitudes as functions of wind speed and fetch. The dependence of slope and intercept on fetch for the second and the third modes are opposite; with the slope increasing with fetch and the intercept decreasing. For the fourth mode, both the slope and the intercept of the regression lines increase with fetch. This difference in behavior for the various modes arises from the different nature of the aerosol. The second and third modes still have a contribution from continental aerosols, while the fourth mode consists almost exclusively of fresh sea spray particles. The fit procedures yielded the following mode amplitudes and mode widths as a function of fetch $X$ (in meters), and wind speed $U$ (in $\mathrm{m} / \mathrm{s}$ ):

$$
\begin{aligned}
& A_{1}=-24350 \operatorname{Ln} X+345901, \\
& A_{2}=10^{[(0.03 \operatorname{Ln} X-0.282) U-0.385 \operatorname{Ln} X+5.25]}, \\
& A_{3}=10^{[(0.045 \operatorname{Ln} X-0.398) U-0.47 \operatorname{Ln} X+3.25]}, \\
& A_{4}=10^{[(0.0095 \operatorname{Ln} X-0.0593) U+0.1424 \operatorname{Ln} X-4.3417]}, \\
& C_{1}=-0.19 \operatorname{Ln} X+3.2, \\
& C_{2}=-0.148 \operatorname{Ln} X+2.883, \\
& C_{3}=-0.295 \operatorname{Ln} X+4.55, \\
& C_{4}=10 .
\end{aligned}
$$

Equations (2) through (9) apply to $3000 \mathrm{~m}<X$ $<120000 \mathrm{~m} 3 \mathrm{~m} / \mathrm{s}<U<18 \mathrm{~m} / \mathrm{s}$ and $\mathrm{RH}<98 \%$.

\section{Limit of Validity and Performance of the Mediterranean Model}

Figure 6 shows comparisons between observed and modeled size distributions for fetches of 3,13 , and $25 \mathrm{~km}$. The modeled distributions show good agreement with the experimental data.

Figure 7 shows a comparison between the Mediterranean modeled distribution, the prediction of the Ireland model, both for the largest fetches for which they apply (120 and $200 \mathrm{~km}$, respectively), and the spectrum predicted by NAM. The three curves are very close between 0.7 and $10 \mu \mathrm{m}$, which indicates that for large fetch, the two coastal aerosol models closely approach the open ocean NAM prediction. Deviations up to a factor of 10 are observed for submicron particles for which the removal rate is too slow to allow for complete equilibrium between production and removal, i.e., the transition to an infinite fetch condition. Hoppel et al. ${ }^{26}$ report the time required to reach equilibrium 


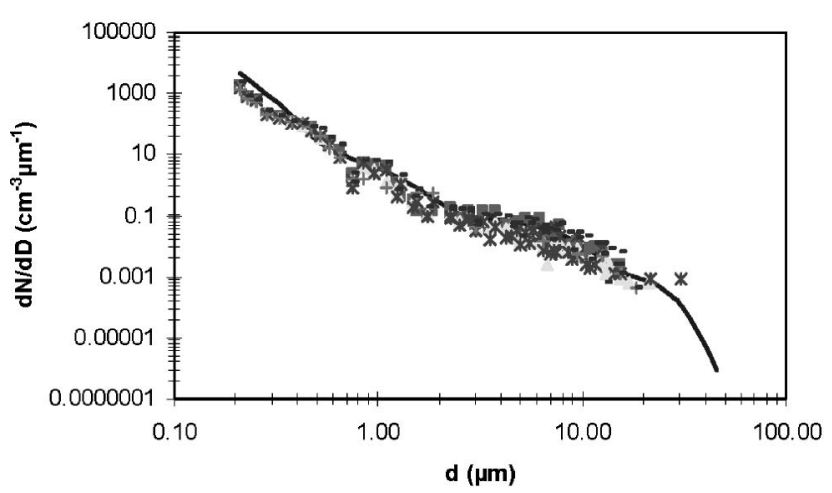

(a)

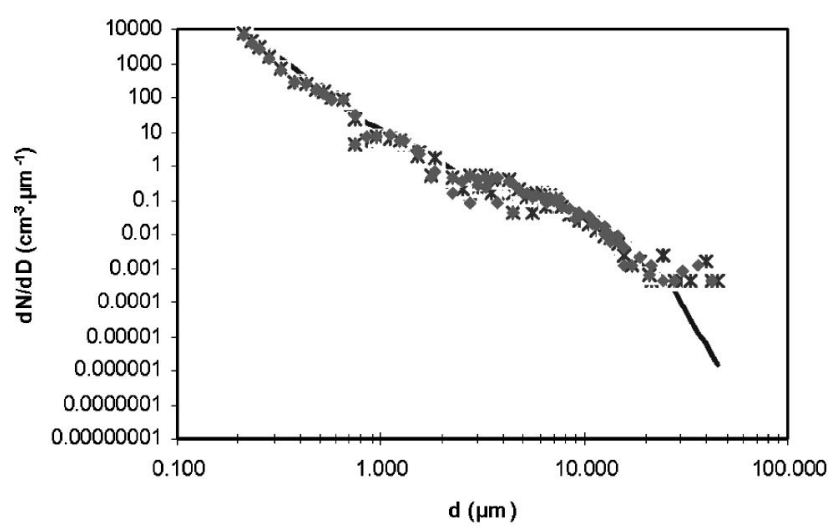

(b)

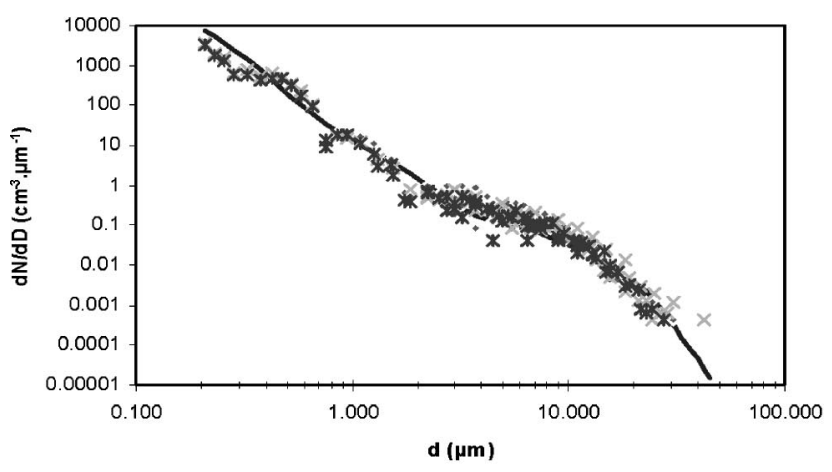

(c)

Fig. 6 (a) Measured particle size distribution and model predictions (solid line) for a $3-\mathrm{km}$ fetch and for wind speeds between 9.5 and $10.5 \mathrm{~m} / \mathrm{s}$. (b) Measured particle size distribution and model predictions (solid line) for a 13-km fetch and for wind speeds between 7.5 and $9.5 \mathrm{~m} / \mathrm{s}$. (c) Measured particle size distribution and model predictions (solid line) for a $25-\mathrm{km}$ fetch and for wind speeds between 12.5 and $13.5 \mathrm{~m} / \mathrm{s}$.

to be four days for $1-\mu \mathrm{m}$ particles. Deviations for particles larger than $10 \mu \mathrm{m}$ are due to the addition of the fourth mode in the Mediterranean model, which is not included in NAM or the Inisheer model.

The mean error of the model for predicting the aerosol concentration has been estimated from the deviation of the model results from the experimental data. The results are presented in Table 1, where the reliability of the model prediction is expressed as the maximum factor by which the modeled aerosol concentration differs from the experi-

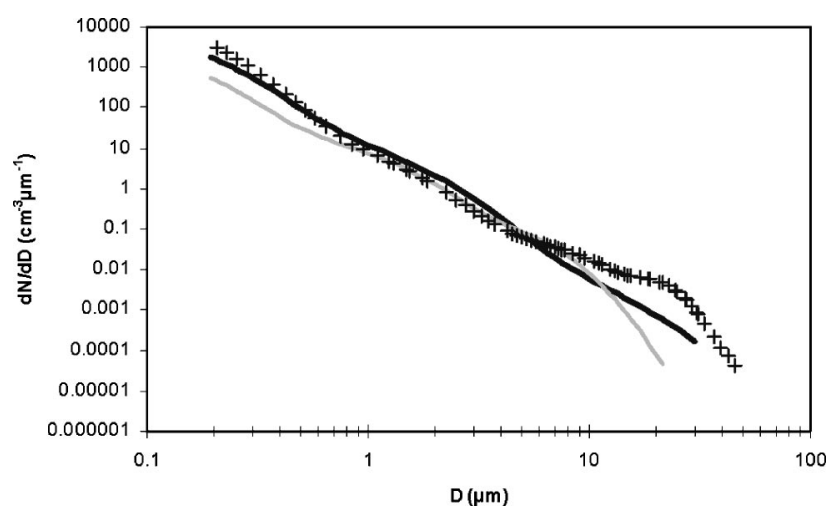

Fig. 7 Comparison of the predictions by NAM (thick line), the Ireland model (gray line) for a fetch of $200 \mathrm{~km}$, and the Mediterranean model for a fetch of $120 \mathrm{~km}$ (crosses) for a wind speed of $10 \mathrm{~m} / \mathrm{s}$.

mental concentration ( $68 \%$ confidence). Figure 8 illustrates the performance of the model for $5-\mu \mathrm{m}$ particles against all the data (i.e., for all wind directions). The line $y=x$ represents ideal model performance and the standard deviation from this line is 0.4 , which means that the model predicts the concentration of $5-\mu \mathrm{m}$ particles to within a factor of 1.5 (68\% confidence limit).

Table 1 shows that the model predictions are better for the second and the third modes (the entries for 0.5- and 5 - $\mu \mathrm{m}$ particles), but have a slightly smaller accuracy for the fourth mode (20- $\mu \mathrm{m}$ particles). However, the largest error is found for the first mode $(0.2-\mu \mathrm{m}$ particles).

The very large aerosols are produced by breaking waves and surface tearing, and hence are influenced by wind gusts. Generally, the west and northwest winds in the study area are quite gusty, which may result in the relatively large uncertainty of the model for the "giant particles." Furthermore, measurement uncertainties increase for the larger particles due to sampling statistics. The large variation in the concentrations of the particles of the accumulation mode, in particular for very short fetches, is due to the variability of the sources over land, a factor which is difficult to account for in an empirical model.

The model confidence factors (Table 1) for the present study, both MPN ${ }^{15}$ and the Inisheer ${ }^{9}$ studies, are all of the same order of magnitude. This indicates that such empirical models may well describe local variations of the aerosol size distribution as a function of meteorological conditions for a variety of coastal locations.

Table 1 Model performance for different particle sizes: tabulated are the factors to within the difference between the model predictions, and the experimental aerosol concentrations vary, with $68 \%$ confidence and $95 \%$ confidence limit, respectively.

\begin{tabular}{ccc}
\hline \hline $\mathrm{D}(\mu \mathrm{m})$ & $68 \%$ Confidence & $95 \%$ Confidence \\
\hline 0.2 & 2.8 & 4.6 \\
0.5 & 1.70 & 1.72 \\
5 & 1.49 & 1.50 \\
15 & 1.50 & 1.52 \\
20 & 2.0 & 2.22 \\
\hline \hline
\end{tabular}




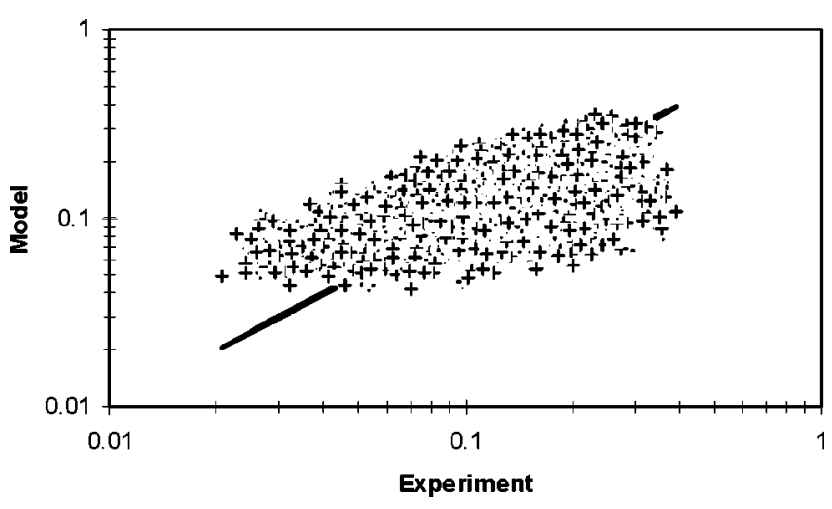

Fig. 8 Scatter plot of the modeled concentrations of $5-\mu \mathrm{m}$ particles versus experimental values. The line denotes ideal model performance.

\section{Comparison Between the Inisheer and the Porquerolles Coastal Aerosol Models}

Aerosol size distributions modeled for the Mediterranean and the Irish coast at fetches of 15,25 , and $100 \mathrm{~km}$ are compared in Fig. 9. A comparison for large fetch has already been presented in Fig. 7. For the shortest fetch, i.e., smaller than $15 \mathrm{~km}$, the aerosol concentrations in the Mediterranean area are significantly higher for all sizes. For a $25-\mathrm{km}$ fetch, the concentrations of particles with sizes around 1 to $2 \mu \mathrm{m}$ are similar, and for particles either smaller than $0.5 \mu \mathrm{m}$ or larger than $5 \mu \mathrm{m}$, the concentrations are larger at the Mediterranean coast than at Inisheer. It is noted that for giant particles, the discrepancies are largely due to the fact that the fourth mode is available only for the Mediterranean model. The differences for small particles are discussed later. For a $100-\mathrm{km}$ fetch, the particle distributions behave as though already observed for large fetches in Fig. 6, i.e., the two coastal models are very close except for both the submicron and the "giant" portion of the aerosol spectrum.

\subsection{Differences in the First Mode}

The amplitude of the first mode, $A_{1}$, describes the accumulation mode aerosol, which is mainly of anthropogenic origin. High concentrations are observed near sources of pollution from densely populated and industrialized areas. In $\mathrm{NAM}^{6}{ }^{6}$ the amplitude $A_{1}$ was parameterized as a function of the residence time of the air mass over the sea, and determined from the air mass trajectories, the visibility, or the radon counts. ${ }^{6}$ Visibility and radon counts are direct measures of the continental influence and the concentrations of submicron particles. The current parameterization, as a function of the fetch, is similar to the residence time method, and in fact the fetch was determined from the air mass trajectories. The problem with this kind of formulation is that $A_{1}$ is not only determined by the residence time, but also by upwind sources.

The importance of the anthropogenic contribution to the aerosol concentrations in the Mediterranean was recently confirmed by chemical analysis using ion chromatography on particles collected with a low pressure cascade impactor during the FETCH campaign in the Golf du Lion ${ }^{27}$ by Sellegri et al. ${ }^{28}$ Measurements made in winds of continental origin at fetches of less than $100 \mathrm{~km}$ showed that the accu-

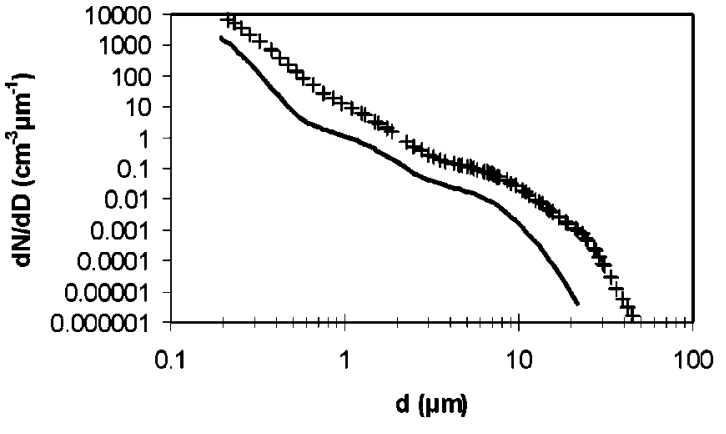

(a)

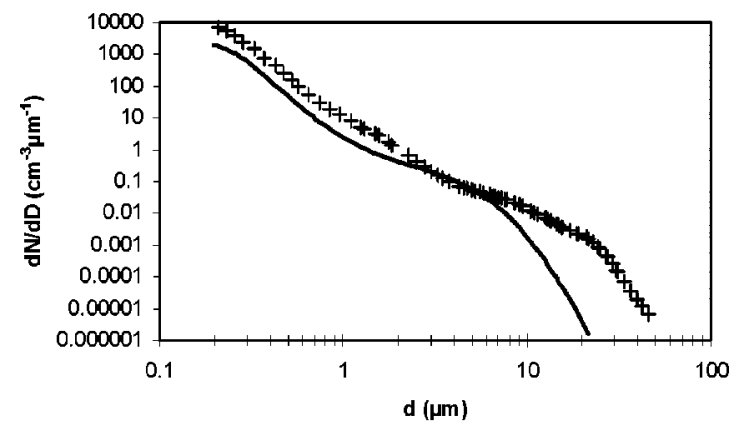

(b)

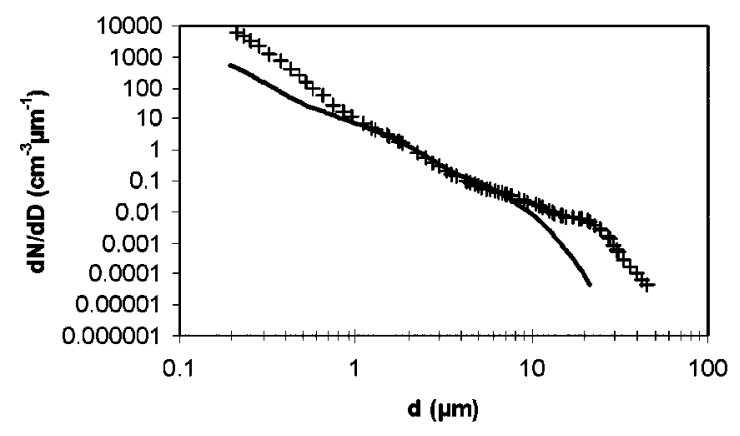

(c)

Fig. 9 (a) Comparison of the Mediterranean model and the Inisheer model for a fetch of $15 \mathrm{~km}$ and a wind speed of $7 \mathrm{~m} / \mathrm{s}$. The crosses represent the Mediterranean model and the line the predictions of the Inisheer model. (b) Comparison of the Mediterranean model (crosses) and the Inisheer model (line) for a fetch of $25 \mathrm{~km}$ and a wind speed of $8 \mathrm{~m} / \mathrm{s}$. (c) Comparison of the Mediterranean model (crosses) and the Inisheer model (line) for a fetch of $100 \mathrm{~km}$ and a wind speed of $10 \mathrm{~m} / \mathrm{s}$.

mulation mode, essentially the first mode of the modeled aerosol spectrum, mainly contains nitrate, ammonium, and non-sea salt sulfates, which indicate an anthropogenic influence.

The slope of the first mode, Eq. (2), is quite similar to that for the Inisheer model (where $A_{1}=-26300 \operatorname{Ln} X$ $+317350)$. The variations of $A_{1}$ with fetch for the Inisheer and the Porquerolles models are shown in Fig. 10. Figure 10 shows that $A_{1}$ is larger in the Mediterranean model because the submicron aerosol concentrations are larger due to upwind sources. For example, for specific west or westsouthwest local wind directions at Porquerolles, the air mass sampled has passed over the Rhone Valley (northeast of Marseille) before turning eastward over the Mediterra- 


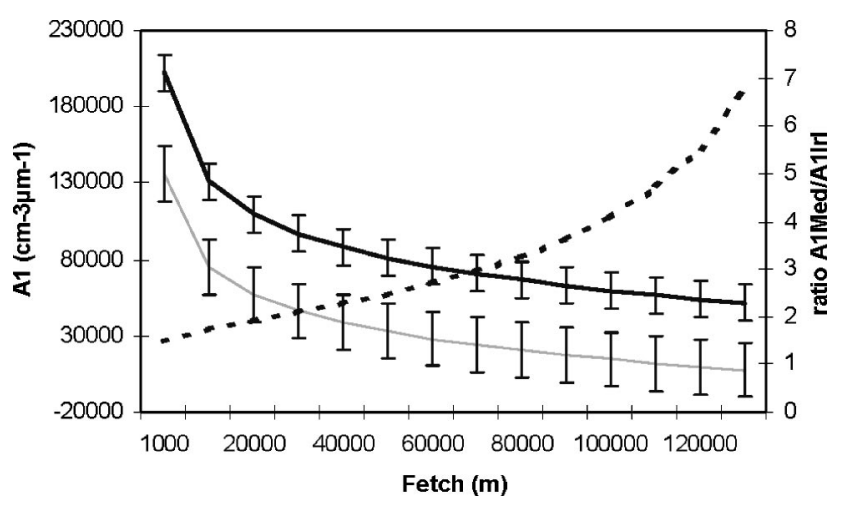

Fig. 10 Fetch variations of the mode amplitude $A_{1}$ for both the Mediterranean model (black line) and the Inisheer model (gray line). The standard error is reported for each model.

nean Sea. The Rhone Valley is a very industrialized and urbanized zone with large emissions of anthropogenic aerosols.

For a generalization of the findings at Inisheer and Porquerolles into a coastal model, it is necessary to introduce a procedure that accurately identifies and parameterizes the continental sources of the smaller particles that determine the observed concentrations given by the intercept. The slope describes the removal rate of the particles, which is similar for Inisheer and Porquerolles.

During periods of low wind speed, the production of sea spray is negligible. This implies that the extinction strongly depends on the concentrations of the first mode, which vary with the meteorological conditions. For example, Piazzola and Despiau ${ }^{17}$ showed that during episodes of very low wind speed periods, the accumulation mode concentrations tend to increase with time because the particles accumulate in the area by lack of further dispersion. Similar observations were made by Vignati et al., ${ }^{14}$ who reported the increase of both the fine and coarse fractions with wind speed. In contrast, for short fetches they decrease. Another factor affecting the concentrations of submicrometer particles is rain. Wet deposition is the most important removal process for atmospheric aerosol particles. The consequence of the washout effect is a very low background aerosol.

\subsection{Second and Third Mode of the Aerosol Models: Generation of Marine Aerosols in the Coastal Zone}

The Mediterranean and Inisheer models predict similar concentrations of particles with sizes between about 0.5 and $5 \mu \mathrm{m}$ for fetches of $25 \mathrm{~km}$ and larger (see in Figs. 7 and 9). For smaller fetches, the concentrations are significantly different as particles in this radius range are mainly described by the second and third modes of the models. The concentration differences at smaller fetches may be due to both the continental influence (discussed in the previous section) and the production of sea spray. The surface production of sea spray by breaking waves depends, among others, on wind speed. The slope and the intercept of the concentration/wind speed regressions [in $\log (\mathrm{dN} / \mathrm{dD})$ versus U] derived for various fetches are presented in Table 2 for particles with a diameter of $5 \mu \mathrm{m}$. The concentrations at Inisheer and Porquerolles are in reasonable agreement. The
Table 2 Slope and intercept of the concentration-wind speed regression $(\log N=a U+b)$ for $5-\mu \mathrm{m}$ particles in the Mediterranean at various fetches.

\begin{tabular}{cccc}
\hline \hline Fetch $(\mathrm{km})$ & Slope $(\mathrm{a})$ & Intercept $(\mathrm{b})$ & Wind speed interval \\
\hline 100 & $0.100 \pm 0.013$ & $-2.25 \pm 0.03$ & $5-16$ \\
25 & $0.060 \pm 0.003$ & $-1.66 \pm 0.06$ & $5-19$ \\
13 & $0.048 \pm 0.003$ & $-1.20 \pm 0.06$ & $2-11$ \\
6 & $-0.023 \pm 0.003$ & $-1.10 \pm 0.03$ & $3-11$ \\
3 & $-0.04 \pm 0.06$ & $-0.48 \pm 0.03$ & $2-11$ \\
\hline \hline
\end{tabular}

5 - $\mu \mathrm{m}$ particles are primarily described by the third mode of the models, and are predominantly of marine origin. The slope describes the wind speed dependence and the intercept represents the concentration when the wind speed approaches zero. For the largest fetches $(100$ and $200 \mathrm{~km}$ in Tables 2 and 3, which correspond to the Mediterranean and Ireland data, respectively), the slopes and intercepts are similar. This indicates, as noted before, that the two coastal models converge toward a common value for open ocean conditions.

For shorter fetches, the intercepts are larger in the Mediterranean, indicating the larger concentrations. By lack of additional data to explain these, we can only speculate on the reasons for the difference. In particular, the geographic location and the oceanographic and atmospheric conditions play a role.

The large differences found in the intercepts at short fetches between the two datasets may be directly and indirectly due to a seasonal influence on the aerosol generation processes. First, as a direct influence of the season, the higher atmospheric concentrations in the Mediterranean coastal zone can be related to atmospheric stability, which in turn depend on the value of the air-sea temperature difference (ASTD). The Mediterranean data were mainly recorded during unstable atmospheric conditions (i.e., negative ASTD: warm sea, low air temperature), while the Inisheer data largely corresponded to stable (cold sea, higher air temperature) or near-neutral stability conditions. Atmospheric stability influences the efficiency of turbulent vertical mixing and thereby the vertical profiles of aerosol concentration (and hence extinction). ${ }^{29}$ This effect shows up most clearly in the concentration profiles in low wind periods. $^{29}$ Atmospheric stability also influences whitecapping, ${ }^{30}$ which in turn is directly related to sea salt aerosol production.

Table 3 Slope and intercept of the concentration-wind speed regression $(\log N=a U+b)$ for $5-\mu \mathrm{m}$ particles at Inisheer at various fetches.

\begin{tabular}{cccc}
\hline \hline Fetch $(\mathrm{km})$ & Slope $(\mathrm{a})$ & Intercept $(\mathrm{b})$ & Wind speed interval \\
\hline 200 & $0.105 \pm 0.006$ & $-2.31 \pm 0.06$ & $3-14$ \\
22 & $0.080 \pm 0.011$ & $-2.15 \pm 0.06$ & $5-10$ \\
15 & $0.042 \pm 0.017$ & $-2.080 \pm 0.093$ & $2-8$ \\
10 & $0.020 \pm 0.009$ & $-1.980 \pm 0.085$ & $5-11$ \\
\hline \hline
\end{tabular}


In addition, as an indirect consequence of the season, it is likely that the value of the intercept depends on the probability and frequency of occurrence of high wind speed periods. For experiments in the winter, the time between periods with enhanced wind speed and increased aerosol generation through wave breaking is much smaller than in the summer. Hence, in the winter more frequent atmospheric loading occurs with aerosols of all sizes. The effect of frequent loading is more pronounced for large particles with short residence times (thus making them more sensitive to wind speed variations) than for smaller particles with longer residence times and relatively slowly changing concentrations. This would explain why, at medium and large fetches, the concentrations of particles with sizes between 0.5 and $5 \mu \mathrm{m}$ at the two sites are in reasonable agreement, whereas for particles with larger sizes the spectra diverge. During the Inisheer experiments only a few periods occurred with elevated wind speeds. ${ }^{9}$ At the Porquerolles site the wind speed exceeded $15 \mathrm{~m} / \mathrm{s} 13 \%$ of the time. During the Inisheer experiments the wind speed was never higher than $14 \mathrm{~m} / \mathrm{s} .{ }^{9}$ Variable wind speeds also result in changes in the wave generation process. During periods of constant wind speed, wind and wave fields are in balance resulting in "aged" waves. Variable winds result in younger waves that are steeper and break more frequently. Hence there are more whitecaps and more sea salt is produced.

The variation of the sea salt concentrations with the wind speed (given by the slopes) for different fetches are presented in Tables 2 and 3. The data show that the slope of the wind speed/concentration regressions are slightly larger for the Inisheer model for all fetches. This is probably due to the wind speed range encountered during the experiments. Indeed, on comparing the slopes of the wind speed/ concentration regressions in three different geographical locations in the Northern hemisphere, Piazzola, Van Eijk, and De Leeuw ${ }^{9}$ suggest a correlation between the slope and the maximum wind speed encountered during the experiments, i.e., the larger the maximum wind speed, the lower the slope.

In addition, the slope of these plots results from a balance between two processes: production of sea spray aerosol (increasing with wind speed and resulting in a positive slope ${ }^{31}$ ) and removal of atmospheric aerosol particles (more effective with wind speed and resulting in a negative slope $\mathrm{e}^{17}$ ). By comparing the slopes of the wind speed/ concentration regressions calculated at different geographical locations in the northern hemisphere, Piazzola, Van Eijk, and De Leeuw ${ }^{9}$ showed that the larger slopes are found at Inisheer. This larger slope implies a relatively large contribution of marine aerosols, which could be due to an increased production as compared to the other sites. In particular, the Inisheer data was obtained in August and September during a phytoplankton bloom, which commonly leads to an increase of gas dissolved in the sea, that could in turn enhance particle production. ${ }^{32}$ This could explain the larger slope of the wind speed/concentration plots observed in Ref. 9 in Ireland compared to the North Sea data, ${ }^{15}$ Smith, Consterdine, and Park ${ }^{31}$ in the Hebrides, and the aerosol data recorded by De Leeuw, Van Eijk, and Noordhuis ${ }^{33}$ in the remote North Atlantic.

\subsection{Fourth Mode in the Mediterranean Aerosol Model}

The addition of the fourth mode to NAM to describe the concentrations and effects of very large particles was proposed by De Leeuw. ${ }^{24}$ This size fraction (with diameters larger than 10 to $20 \mu \mathrm{m}$ ) mainly consist of so-called spume drops, which are produced by direct tearing from the wave tops at wind speeds larger than about $9 \mathrm{~ms}^{-1}$ (as discussed by Monahan et al. ${ }^{34}$ ). De Leeuw et al. ${ }^{35}$ argued that NAM underestimates the concentration of the spume droplets resulting in an estimate of the IR extinction that is too low. As already mentioned in the introduction, the Advanced Navy Aerosol Model (ANAM) ${ }^{8}$ aims at resolving this underestimate by the introduction of a fourth mode. In analogy with ANAM, we have also added a fourth mode to the Mediterranean model. The optimized center radius for the Mediterranean model $(\mathrm{C} 4=10 \mu \mathrm{m})$ corresponds well with the $\mathrm{C} 4=8 \mu \mathrm{m}$ used in the preliminary version of ANAM. ${ }^{36}$ The Inisheer model does not include a fourth mode, which explains in part some of its discrepancies with the Mediterranean model, at least for large particles. Because higher wind speeds were encountered at Porquerolles, this dataset is suitable for the introduction of a fourth mode to describe the observed aerosol size distribution. At Inisheer the maximum wind speed encountered was $14 \mathrm{~ms}^{-1}$; at these wind speeds the spume droplet production is relatively unimportant.

\section{Discussion of the Aerosol Model}

Discrepancies between the two coastal models occur for aerosols with radii equal to and larger than $5 \mu \mathrm{m}$. The linear regression of concentrations versus wind speed shows that the intercepts of the regression lines are substantially larger in the Mediterranean (Tables 2 and 3). The relatively large marine aerosol concentrations observed in the Mediterranean may be due to more intensive biological activity. Indeed, biological activity is primarily induced by light, and furthermore, depends strongly on the input of nutrients into the sea. ${ }^{32}$ Whereas rivers provide the largest amounts of nutrients, the atmosphere may account for up to $40 \%$ of the total inputs ${ }^{37}$ in the coastal zone. Riverine inputs are most effective close to the coast, whereas atmospheric inputs are not only very large close to the land-sea transition, ${ }^{38}$ but (due to atmospheric transport) also at larger distances from the coastline. Atmospheric inputs are largely an anthropogenic perturbation to the coastal ecosystem leading to relatively high biological activity. ${ }^{38}$ High concentrations of pollutants have been observed in the Mediterranean area, in particular from the run-off after a rain. ${ }^{39}$ The pollution from urbanized coastal sites with large population densities, such as the Mediterranean study area, may cause an excess of phosphate and nitrate compounds resulting in eutrophication. Combined with the high intensity of solar radiation in the Mediterranean area, this induces substantial enhancement in both chlorophyll and phytoplankton concentrations. ${ }^{40}$ Biological studies conducted in the Mediterranean area, i.e., in Toulon Bay and in Hyeres Bay, have indeed revealed an excess in nutrients and eutrophication processes throughout the year. ${ }^{40}$ The effects of marine pollution are thus not limited to a specific period of the year 
with a limited duration, as is the case for a phytoplankton bloom. Biologically enhanced production of sea spray may also occur in the winter.

For short fetch, additional effects can play a role. Increased pollution has been observed after a strong rainy episode in bays and estuaries. ${ }^{39}$ Also, whitecap cover may be enhanced in the shallow water near the coast. ${ }^{13}$ Both the increase in the whitecap cover and the enhanced generation due to the biologic activities induced by pollution, contribute to the production of marine aerosol and can occur throughout the year. The biological effects could explain the relatively large dependence of the aerosol concentration on the wind speed found in the Mediterranean and in Inisheer when compared to other sites, such as The Hebrides. ${ }^{9}$

Seasonal variations in aerosol production can also arise from the influence of the sea surface temperature on bubble-mediated sea spray aerosol production. Walsh and Mulhearn $^{41}$ note that the concentrations of bubbles larger than $100 \mu \mathrm{m}$ (the precursors of jet droplets) increase with sea surface temperature. In accordance with this, results obtained in a simulation tank by Bowyer, Woolf, and Monahan $^{42}$ show that the concentrations of jet drops (with radii larger than $2 \mu \mathrm{m}$ ) increase with the water temperature. In addition, Blanchard ${ }^{43}$ suggested that when the sea temperature increases, the ejection height of the jet drops is larger, thereby making it easier for these droplets to be captured by the turbulent airflow over the waves and thus be transported aloft. A model for the bubble-mediated production of sea spray aerosol as a function of the sea water temperature has been formulated by Martensson et al. ${ }^{20}$ Their model suggests larger production at higher water temperatures, and thus, a seasonal variation dependent on the specific geographical location. In addition, this effect would lead to generally higher aerosol production in the Mediterranean than at Inisheer. The relatively large marine pollution in the Mediterranean area, combined with biological and water temperature effects when compared to the Inisheer site, may thus induce greater aerosol production all year long, implying a high background level and hence, a larger intercept of the regression line.

\section{Code MEDEX}

In the code MEDEX the Mediterranean aerosol model was coupled to a $\mathrm{Mie}^{44}$ program to calculate the aerosol extinction for the Mediterranean coastal zone. The extinction coefficient, $k\left(\mathrm{~km}^{-1}\right)$, of electromagnetic radiation by aerosol particles is given by the expression:

$k=\int Q(r, \lambda, m) \cdot N(r) \cdot \pi r^{2} d r$,

where $N(r)$ is the concentration of particles of radius $r$, and $Q(r, \lambda, m)$ is the extinction efficiency of a particle (assumed to be spherical) with radius $r$ and complex refractive index $m$ at wavelength $\lambda$. The MEDEX model calculates the aerosol size distribution $N(r)$ from the Mediterranean aerosol model, or alternatively, accepts a measured aerosol size distribution. The output of MEDEX has a format compatible with MODTRAN, and hence, can be used to directly supply MODTRAN with aerosol extinction param-

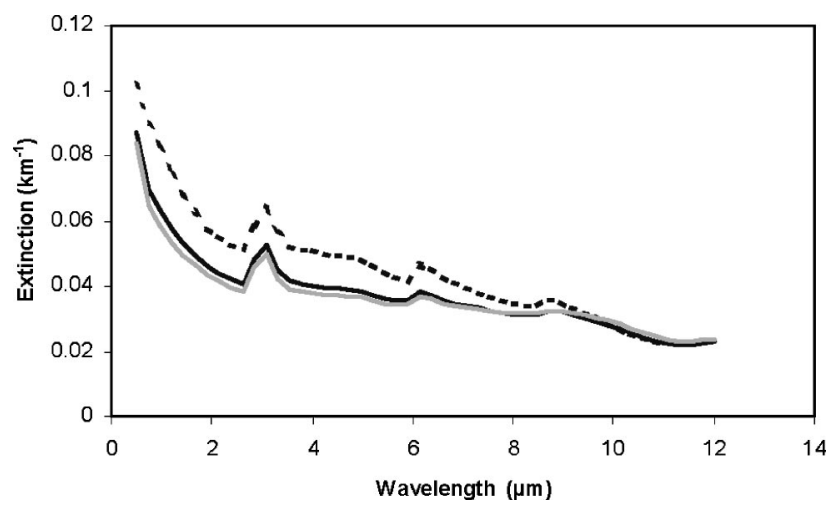

Fig. 11 Variations of the extinction coefficient versus wavelength for a wind speed of $5 \mathrm{~m} / \mathrm{s}$ and for different fetches. The dashed curve represents a fetch of $5 \mathrm{~km}$, while the black one is for a fetch of $15 \mathrm{~km}$ and the gray line was recorded for $25-\mathrm{km}$ fetch.

eters. In addition, MEDEX offers an option to calculate the vertical profile of aerosol extinction, from 0 to $25 \mathrm{~m}$ in height, using the vertical humidity profile.

\section{MEDEX Extinction Calculations}

This section describes the predictions of the MEDEX aerosol extinction code. To assess coastal effects, a comparison is made with extinction values published for different geographical locations in the northern hemisphere.

\subsection{Extinction During Light Wind Periods}

The influence of continental sources on extinction is particularly observed during periods of low wind speeds, when marine production is small. In Fig. 11, extinction coefficients calculated at a wind speed of $5 \mathrm{~ms}^{-1}$ for fetches of 5 , 15 , and $25 \mathrm{~km}$ are plotted versus wavelength. First, Fig. 11 shows that the extinction increases toward shorter wavelengths, implying that the extinction coefficient in the 3 to 5 $\mu \mathrm{m}$ band is larger than in the 8 to $12 \mu \mathrm{m}$ band. The strong increase below $2 \mu \mathrm{m}$ is due to submicron continental particles in the first mode. This is characteristic for continental aerosols with a strong decrease of the particle concentrations toward larger sizes (representing the particle size distribution as a power law function, the exponent for a continental aerosol size distribution would be on the order of $-4)$. The gradual removal of aerosol particles as the fetch increases results in a decrease of the extinction as evidenced in Fig. 11. The decrease is observed at all wavelengths, but is relatively more important at shorter wavelengths, where small (continental) aerosols contribute more to the extinction. Their removal is less counterbalanced by the low production of marine aerosols at this low wind speed.

\subsection{Extinction Calculations for High Wind Speed Periods at Various Fetches}

Figure 12 shows the variation of the extinction coefficients versus wavelength, calculated using MEDEX, for fetches varying from 3 to $100 \mathrm{~km}$, for wind speed of $12 \mathrm{~ms}^{-1}$. Figure 12 clearly shows that the extinction increases with fetch at all wavelengths. This indicates that the enhanced production of sea spray compensates for the dilution of continental particles by advection, ${ }^{14}$ even at smaller wave- 


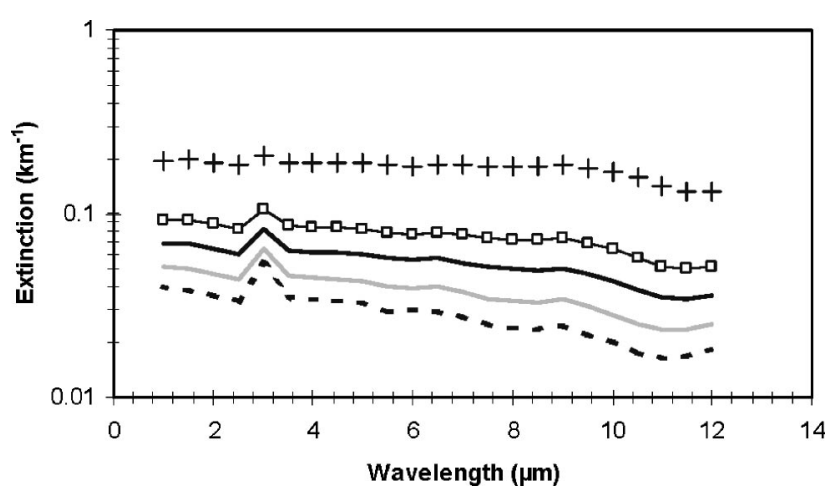

Fig. 12 Variations of the extinction coefficient versus wavelength for a wind speed of $12 \mathrm{~m} / \mathrm{s}$ and for different fetches. The crosses represent a $100-\mathrm{km}$ fetch, while the squares show extinction coefficients at a $25-\mathrm{km}$ fetch, the black one is for a fetch of $13 \mathrm{~km}$, the gray line deals with a $6-\mathrm{km}$ fetch, and the dashed curve gives the extinction for a $3-k m$ fetch.

lengths. The extinction values predicted using the MEDEX code are larger than those usually measured in the study $\operatorname{area}^{13,45}$ and other geographical locations. ${ }^{46}$ For example, MEDEX predictions were compared with extinction values published by Tolliday et al., ${ }^{47}$ which are based on aerosol measurements at about 10-m height at the Hebrides. Except for low wind speed episodes at short fetch, the MEDEX model predicts substantially larger extinctions than those measured at the Hebridean coast (almost a factor-of- 3 difference). For wind speed of $17 \mathrm{~m} / \mathrm{s}$, the mean extinction at $10-\mathrm{m}$ height is around $0.13 \mathrm{~km}^{-1}$ in the Mediterranean for a fetch of $25 \mathrm{~km}$ and $0.55 \mathrm{~km}^{-1}$ for a fetch of $100 \mathrm{~km}$, while Tolliday et al. ${ }^{47}$ present an extinction around 0.18 $\mathrm{km}^{-1}$ at $10-\mathrm{m}$ height for wind speeds between 15 and 20 $\mathrm{m} / \mathrm{s}$. The measurements on the Hebridean coast were made in purely marine air masses, representative of open ocean conditions.

The higher extinction values calculated with MEDEX are due to the addition of the fourth mode. For thermal infrared wavelengths, the effect of the fourth mode is expected to be even higher. This has also been observed in other studies. The $10-\mu \mathrm{m}$ extinction calculated by the ANAM model is about a factor of 2 higher $^{36}$ than the one given by NAM due to the additional fourth mode. Similar enhancement was demonstrated by the addition of giant aerosol particles $(r>6 \mu \mathrm{m})$ measured with Rotorod impaction samplers ${ }^{48}$ to simultaneously measured PMS spectra. The $10-\mu \mathrm{m}$ extinction increased by roughly a factor of $3.48,49$

\section{Summary and Conclusion}

On the basis of a dataset obtained on the island of Porquerolles near the French Mediterranean Coast, an empirical aerosol model for the coastal zone has been developed. The aerosol model accounts for both the generation and the transport and removal of aerosols. Advection is particularly important in the case of land winds. This aerosol model, coupled with a Mie program, is called MEDEX and allows for an improvement in the prediction of the aerosol extinction in the coastal zone as compared to the more generally used NAM model ${ }^{6}$ that applies to the open ocean. The main improvements of MEDEX are the introduction of the fetch as the governing parameter, and the addition of the fourth mode in the modeled aerosol spectrum. The introduction of the fetch results in a better parameterization of coastal effects, such as the generation and dispersion processes of the aerosol particles. In particular, this allows for improvement in the extinction predictions for moderate and low wind speeds. The extinction predictions for high wind speed periods are improved through the addition of a fourth mode to the modeled aerosol size distribution. This is essential to account for the generation of the "giant" spume drops by the direct action of the wind on the wave crests. The fourth mode results in larger extinction coefficients in the thermal infrared than previously reported in the literature. ${ }^{46}$

One of the objectives of the present work is to show to what extent the coastal model for the Mediterranean can be used to predict the aerosol extinction at any geographical location in the northern hemisphere. Thus, a comparison between the aerosol size distributions predicted for two coastal sites of Inisheer and the Mediterranean was conducted.

The two coastal areas showed large differences in the aerosol concentration for submicron aerosol particles, i.e., the continentally influenced first mode of the modeled aerosol spectrum. The differences in the first mode are due to the larger anthropogenic emissions near the Mediterranean coast as compared to the Inisheer site, but they may also be a consequence of seasonal variations of the generation processes. The discrepancies between the two models found in the first mode are reduced for medium and large fetches, where the effect of the continental particles becomes relatively less important. For relatively short fetches, the concentrations for aerosols of all sizes in the Mediterranean coastal area are substantially larger than at the Irish North Atlantic Coast, as clearly shown in Fig. 9. This is to a large extent also explained by the influence of anthropogenic sources on the Mediterranean Coast in the south of France.

In contrast, for medium and large fetches, a reasonable agreement is found at the two coastal sites between aerosol spectra for sizes between 0.5 and $5 \mu \mathrm{m}$ (corresponding to the second and third modes of the model). This is to a large part due to the fact that particles with these sizes are predominantly of marine origin and have larger residence times in the atmosphere. In particular, a study of the wind speed dependence of the 5- $\mu \mathrm{m}$ concentrations shows a reasonable agreement between the slope coefficients for all fetches in both areas, although the intercepts derived from the Mediterranean data are larger. This may be in part related to a larger biological activity in that area. Furthermore, for open ocean conditions, a reasonable agreement is found between the two coastal areas studied in the present article and the original NAM, although minor differences exist at small and large particle radii.

For aerosol sizes greater than $5 \mu \mathrm{m}$, larger discrepancies between the Inisheer and Mediterranean models occur. The linear regressions of concentration versus wind speed show that the intercepts of the regression lines are substantially larger in the Mediterranean. To a large extent, these discrepancies are directly or indirectly related to the seasonal variations of the sea salt aerosol generation. The Inisheer data were recorded during the summer, while the Mediterranean experiments took place between November 2000 and February 2001, i.e., in the winter. During the summer 
experiments at Inisheer, the wind speed was most of the time relatively low, resulting in low production rates (which resulted in small background concentrations). Seasonal effects not only influence aerosol generation through the sea temperature and biological activity, but also the atmospheric aerosol loading due to the more frequent occurrence of moderate and high wind speeds in the winter as compared to summer conditions. In addition, the effect of the pollution in the Mediterranean may explain a higher marine aerosol production in the winter time compared to other geographical locations. ${ }^{9}$ The consequence is a relatively large background observed in the Mediterranean aerosol concentrations.

\section{Acknowledgments}

The experimental campaign on Porquerolles Island was sponsored by the French Ministry of Defense under contract number 99-42-144-00-470-35-15. The authors wish to thank Dr. Y. Hurtaud (DGA) for this support. The contribution of TNO was supported by the Dutch Ministry of Defense and the analysis was part of KM Program V035, Project A99KM617. We are grateful to Ing. L. H. Cohen for setting up the aerosol measurements at Porquerolles. Dr. Piazzola wishes to express his gratitude to Mr. T. Missamou for his helpful work during the campaign and to Mr. T. Bourdelles for his help in the conception of the software.

\section{References}

1. A. Berk, L. S. Bernstein, and D. C. Robertson, "MODTRAN: A moderate resolution model for LOWTRAN 7," Air Force Geophysics Laboratory Technical Report GL-TR-89-0122, Hanscom AFB, MA (1989).

2. D. R. Jensen, S. G. Gathman, C. R. Zeisse, C. P. McGrath, G. de Leeuw, M. H. Smith, P. A. Frederickson, and K. L. Davidson, "Electro optical propagation assessment in coastal environments (EOPACE): Overview and initial accomplishments," Opt. Eng. 40(8), 1486-1498 (2001)

3. S. M. Doss-Hammel, C. R. Zeisse, A. E. Barrios, G. de Leeuw, M. Moerman, A. N. de Jong, P. A. Frederickson, and K. L. Davidson, "Low altitude infrared propagation in a coastal zone: refraction and scattering," Appl. Opt. (in press).

4. J. L. Forand, D. Dion, M. Duffy, S. G. Gathman, K. Littfin, A. N. Jong, G. De Leeuw, and K. L. Davidson, "An extensive analysis of low-level IR transmission measurements taken over a $15 \mathrm{~km}$ path during EOPACE with IRBLEM," Proc. SPIE 3433, 90-101 (1998)

5. G. J. Kunz, M. M. Moerman, and A. M. J. Van Eijk, "ARTEAM, advanced ray tracing with earth atmospheric models," Proc. SPIE 4718, 397-404 (2002)

6. S. G. Gathman, "Optical properties of the marine aerosol as predicted by the Navy aerosol model," Opt. Eng. 22(1), 57-62 (1983).

7. S. G. Gathman, "A preliminary description of NOVAM, the Navy Oceanic Vertical Aerosol Model," NRL Report no. 9200 (1989).

8. S. G. Gathman and A. M. J. Van Eijk, "Characterizing large aerosols at the lowest levels of marine atmosphere," Proc. SPIE 3433, 41-52 (1998)

9. J. Piazzola, A. M. J. Van Eijk, and G. De Leeuw, "An extension of the Navy Aerosol Model to coastal areas," Opt. Eng. 39(6), 1620-1631 (2000).

10. M. Tanguy, H. Bonhommet, M. L. Autric, and P. Vigliano, "Correlation between the aerosol profiles measurements, the meteorological conditions and the atmospheric I.R transmission in a Meditterranean atmosphere," Proc. SPIE 1487, 172-184 (1991).

11. S. A. Hsu, "A mechanism for the increase of wind stress (drag) coefficient with wind speed over water surfaces: A parametric model," $J$. Phys. Oceanogr. 16, 144-150 (1986).

12. G. J. Komen, S. Hasselmann, and K. Hasselmann, "On the existence of a fully developed wind-sea spectrum," J. Phys. Oceanogr. 14 1271-1285 (1984)

13. J. Piazzola, "Etude de la distribution verticale des particules d'aérosols au voisinage de l'interface mer-air en zone côtiere Méditerranéenne," PhD thesis, University of Toulon-Var, France (1996).

14. E. Vignati, G. de Leeuw, M. Schulz, and E. Plate, "Characterization of aerosols at a coastal site near Vindeby (Denmark)," J. Geophys. Res. 104(C2), 3277-3287 (1999).

15. A. M. J. Van Eijk and G. De Leeuw, "Modeling aerosol particle size distributions over the North sea," J. Geophys. Res. 97(C9), 1441714429 (1992)

16. J. W. Fitzgerald, "Approximation formulas for the equilibrium size of an aerosol particle as a function of its dry and composition and the ambient relative humidity," J. Appl. Meteorol. 14, 1044-1049 (1975).

17. J. Piazzola and S. Despiau, "Contribution of marine aerosols in the particle size distributions observed in Mediterranean coastal zone," Atmos. Environ. 31(18), 2991-3009 (1997).

18. C. D. O'Dowd and M. H. Smith, "Physical properties of aerosols over the Northeast Atlantic: evidence for wind-speed-related submicron sea-salt aerosol production," J. Geophys. Res. 98(D1), 1137-1149 (1993).

19. E. D. Nilsson, U. Rannik, E. Swietlicki, C. Leck, P. P. Aalto, J. Zhou, and M. Norman, "Turbulent aerosol fluxes over the Arctic Ocean 2. Wind-driven sources from the sea," J. Geophys. Res. 106, 3213932154 (2001).

20. M. Mårtensson, E. D. Nilsson, G. de Leeuw, L. H. Cohen, and H-C Hansson, "Laboratory simulations of the primary marine aerosol generated by bubble bursting" (submitted for publication).

21. E. L. Andreas, "A new sea spray generation function for wind speeds up to $32 \mathrm{~ms}^{-1}$," J. Phys. Oceanogr. 28, 2175-2184 (1998).

22. S. A. Slinn and W. G. N. Slinn, "Predictions for particle deposition on natural waters," Atmos. Environ. 14, 1013-1016 (1980).

23. J. Piazzola, P. Forget, and S. Despiau, "A sea spray generation function for fetch-limited conditions," Ann. Geophys. 20(1), 121-13 (2002).

24. G. De Leeuw, "Aerosol effects on electro-optical propagation over sea," Proc. SPIE 1971, 2-15 (1993).

25. H. E. Gerber, "Relative humidity parameterization of the Navy Aerosol Model (NAM)," NRL Report no. 8956, National Research Laboratory, Washington DC (1985).

26. W. A. Hoppel, G. M. Frick, and J. W. Fitzgerald, "The surface source function for sea-salt aerosol and aerosol dry deposition to the ocean surface," J. Geophys. Res. (in press).

27. D. Hauser, H. Dupuis, X. Durrieu, C. De Madron, C. Estournel, J. Flamant, P. Pelon, and P. Queffeulou, "La Campagne FETCH: Une expérience l'étude des échanges océan/atmosphère dans les conditions côtières du Golfe du Lion," La Météorologie, 8(29), (2000).

28. K. Sellegri, S. Despiau, and J. Gourdeau, "Chemical composition of marine aerosol in a Mediterranean coastal zone during the FETCH experiment," J. Geophys. Res. (in press).

29. A. K. Goroch, S. K. Burk, and K. L. Davidson, "Stability effects on aerosol size and height distributions," Tellus 32, 245-250 (1980).

30. E. C. Monahan and I. G. O'Muircheartaigh, "Whitecaps and the passive remote sensing of the ocean surface," Int. J. Remote Sens. 7, 627-642 (1986)

31. M. H. Smith, I. E. Consterdine, and P. M. Park, "Atmospheric loadings of marine aerosol during a Hebridean cyclone," $Q$. J. R. Meteorol. Soc. 115, 383-395 (1989)

32. S. A. Thorpe, P. Bowyer, and D. K. Woolf, "Some factors affecting the size distributions of oceanic bubbles," J. Phys. Oceanogr. 22, 382-389 (1992).

33. G. De Leeuw, A. M. J. van Eijk, and G. R. Noordhuis, "Modelling aerosols and extinction in the marine atmospheric boundary layer," Proc. SPIE 1968, 70-80 (1993).

34. E. C. Monahan, C. W. Fairall, K. L. Davidson, and P. J. Boyle, "Observed interrelation between $10 \mathrm{~m}$ winds, ocan whitecaps and marine aerosols," O. J. R. Meteorol. Soc. 109, 375-392 (1983).

35. G. de Leeuw, K. L. Davidson, S. G. Gathman, and R. V. Noonkester, "Modeling of aerosols in the marine mixed layer," Proc. SPIE 1115 287-294 (1989)

36. A. M. J. van Eijk, "The ANAM-3.0 development," TNO Physics and Electronics Laboratory, Report FEL-01-C187 (2001).

37. H. W. Paerl, W. R. Boynton, R. L. Dennis, C. T. Driscoll, H. S Greening, J. N. Kremer, N. N. Rabalais, and S. P. Seitzinger, "Atmospheric deposition of nitrogen in coastal waters: biogeochemical and ecological implications," in Nitrogen Loading in Coastal Water Bodies: An Atmospheric Perspective, R. A. Valigura, R. B. Alexander, M. S. Castro, T. P. Meyers, H. W. Paerl, P. E. Stacey, and R. E. Turner, Eds., pp. 11-52, American Geophysical Union, Washington, DC (2001).

38. G. De Leeuw, L. Spokes, T. Jickells, C. Ambelas Skjøth, O. Hertel, E Vignati, S. Tamm, M. Schulz, L.-L. Sorensen, B. Pedersen, L. Klein, and K. H. Schlünzen, "Atmospheric nitrogen inputs into the North Sea: Effect on productivity" (submitted for publication).

39. C. Germain, Y. Lucas, C. Lamorte, and C. Le Poupon, "Characterization and quantification of transfer in a small coastal mediterranean river during a storm event," 1st French Meeting on Environmental Chemistry, abstract E099, Nancy, Water Institute (2000).

40. J. L. Jamet, G. Bogé, S. Richard, C. Geneys, and D. Jamet, "The zooplankton community in bays of Toulon area (northwest Mediterranean sea, France)," Hydrobiologia 457, 155-165 (2001).

41. A. L. Walsh and P. J. Mulhearn, "Photographic measurements of bubble populations from breaking wind waves at sea," J. Geophys. Res. 92, 14553-14565 (1987).

42. P. A. Bowyer, D. K. Woolf, and E. C. Monahan, “Temperature depen- 
dence of the charge and aerosol production associated with breaking wave in a whitecap simulation tank," J. Geophys. Res. 95(C4), 53135319 (1990).

43. D. C. Blanchard, "The electrification of the atmosphere by particles from bubbles in the sea," Prog. Oceanogr. 1, 71-202 (1963).

44. G. Mie, "Beiträge zur optik trüber medien, speziell kolloidaler metallösungen," Annalen der Physik, 25 (1908).

45. J. Piazzola and S. Despiau, "The vertical variation of extinction and atmospheric transmission due to aerosol particles close above the sea surface in Mediterranean coastal zone," Opt. Eng. 37(6), 1684-1695 (1998).

46. G. De Leeuw, "Aerosol models for optical and IR propagation in the marine atmospheric boundary layer," Proc. SPIE 1487, 130-159 (1991).

47. N. P. Tolliday, M. H. Smith, P. M. Park, and I. E. Consterdine, "A survey of the maritime-aerosol data collected at south uist and the implications for the Lowtran maritime aerosol model," in Atmospheric Propagation in the UV, Visible, IR and MMwave Region and Related Systems Aspects, pp. 1-11, Agard Conference C-P 454, Copenhague (1989).

48. G. De Leeuw, "Vertical profiles of giant particles close above the sea surface," Tellus 38B, 51-61 (1986).

49. G. de Leeuw, "Vertical distributions of sea-spray particles at low heights and calculated extinction coefficients," TNO Physics and Electronics Laboratory, report FEL 1985-33 (1985).

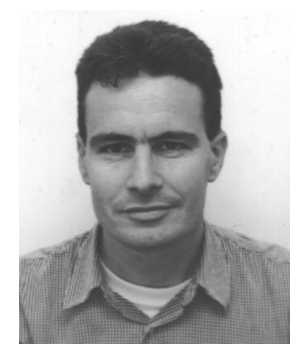

Jacques Piazzola received his $\mathrm{PhD}$ thesis from Toulon University, France, in 1996. In 1997, he worked as a post-doctoral at the TNO Physics and Electronics Laboratory in The Hague, The Netherlands. He joined the Institute of Engineering Sciences (ISITV) of the University of Toulon-Var in 1998, where he currently holds a permanent position of Associate Professor in the Oceanic Engineering Department. His research interests lie in marine boundary layer meteorology with a focus on the air-sea interaction processes and the marine aerosol generation. In particular, one part of his work deals with the influence of the sea state development on the sea spray production and the infrared propagation.

Frédéric Bouchara received his $\mathrm{PhD}$ degree from Toulon University, France, in 1998, where he has been an assistant professor since 1998. His research deals with optical propagation in maritime environment and image processing.

Gerrit de Leeuw received his PhD in 1981 from the University of Amsterdam, The Netherlands. Since then, he has worked at the TNO Physics and Electronics Laboratory, where he is currently responsible for the section Atmospheric Research. In 1989 he spent a sabbatical year at the Naval Postgraduate School in Monterey, California. Since 1996, he has been a Senior Research Fellow of TNO. Since 1999, he has also been a Professor of the University of Sunderland, United Kingdom. His research interests are physical processes in the atmosphere, with applications in the field of radiative effects (climate), pollution (air and water), and atmospheric effects on the performance of electro-optical sensors.

Alexander M.J. Van Eijk received his PhD degree in physical chemistry from Leyden University, The Netherlands. In 1989 he worked as a post-doctoral at the University of California at Riverside in the field of multiphoton ionization spectroscopy. At the end of 1989, he joined the TNO Physics and Electronics Laboratory in The Hague, The Netherlands, where he is a scientist in the ElectroOptical Propagation Group. In 1992, he was a visiting assistant professor at the Ecole Centrale de Nantes in France. His current interest is aerosol physics in the atmospheric surface layer. Research efforts include participation in experimental programs, statistical analysis of the aerosol concentration as function of meteorological parameters, and numerical modeling to provide a physical understanding of the processes that govern the aerosol concentration close to the sea surface. 